\title{
The association between home care visits and same-day emergency department use: a case- crossover study
}

\author{
Aaron Jones MSc, Connie Schumacher RN PhD, Susan E. Bronskill PhD, Michael A. Campitelli MPH, \\ Jeffrey W. Poss PhD, Hsien Seow PhD, Andrew P. Costa PhD
}

Cite as: CMAJ 2018 April 30;190:E525-31. doi: 10.1503/cmaj.170892

Visual abstract available at www.cmaj.ca/lookup/suppl/doi:10.1503/cmaj.170892/-/DC2

See related article at www.cmaj.ca/lookup/doi/10.1503/cmaj.180263

\begin{abstract}
BACKGROUND: The extent to which home care visits contribute to the delay or avoidance of emergency department use is poorly characterized. We examined the association between home care visits and same-day emergency department use among patients receiving publicly funded home care.
\end{abstract}

METHODS: We conducted a populationbased case-crossover study among patients receiving publicly funded home care in the Hamilton-Niagara-HaldimandBrant region of Ontario between January and December 2015. Within individuals, all days with emergency department visits after $5 \mathrm{pm}$ were selected as cases and matched with control days from the pre- vious week. The cohort was stratified according to whether patients had ongoing home care needs ("long stay") or short-term home care needs ("short stay"). We used conditional logistical regression to estimate the association between receiving a home care visit during the day and visiting the emergency department after 5 pm on the same day.

RESULTS: A total of 4429 long-stay patients contributed 5893 emergency department visits, and 2836 short-stay patients contributed 3476 visits. Receiving a home care nursing visit was associated with an increased likelihood of visiting the emergency department after $5 \mathrm{pm}$ on the same day in both long-stay (odds ratio [OR] 1.32, 95\% confidence interval $[\mathrm{Cl}] 1.17-1.48)$ and short-stay patients (OR 1.22, 95\% Cl 1.07-1.39). Stronger associations were observed for less acute visits to the emergency department. No associations were observed for other types of home care visits.

INTERPRETATION: Patients receiving home care were more likely to visit the emergency department during the evening on days they received a nursing visit. The mechanism of the association between home care visits and same-day emergency department use and the extent to which same-day emergency department visits could be prevented or diverted require additional investigation.

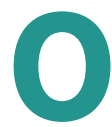

Ider adults are more likely to use the emergency department, have longer lengths of stay in the emergency department and are more likely to be admitted to hospital from the emergency department than younger patents. ${ }^{1-3}$ Despite being highly used by older adults, the emergency department is often not the ideal place for seniors to receive care. Older adults are increasingly presenting to the emergency department with complex care needs that require greater assessment and coordination than the traditional disease-centric and episodic models of care typically permit. ${ }^{4-6}$

Increased access to publicly funded home and community care has been suggested as a way to reduce or prevent unnecessary or avoidable visits to the emergency department. ${ }^{7-9}$ How- ever, evidence on the relation between home care and emergency department use is limited and mixed. Several clinical trials have tested enhanced models of home care and found no effect on emergency department use, whereas increased levels of home care service have been associated with a reduction in emergency department use in patients receiving palliative care. ${ }^{10-12}$

Within health systems, concerns persist that home care has evolved into a task-focused, visit-based, contracted service model that precludes comprehensive practice, and that this taskbased model contributes to silos of care. ${ }^{13}$ There have been calls to shift home care to a more comprehensive, team-based practice model that supports disease management in the home. ${ }^{10,13,14}$ One could assume that a transient association between home 
care visits and emergency department use may exist when home care clinicians have limited flexibility to act beyond a set of predefined tasks during a visit or when they encounter clinical issues beyond the scope of their practice. If home care clinicians identify a clinical issue that they are unable to address during that visit, they may refer the patient to receive care elsewhere on the same day of the visit.

The objective of this study was to investigate the association between home care visits and same-day emergency department use among patients receiving publicly funded home care. We hypothesized that receiving nursing visits during the day would be associated with an increased likelihood of visiting the emergency department during the evening hours of the same day. We hypothesized that there would be no association with other types of home care visits (e.g., personal support, physiotherapy and occupational therapy) given that their traditional scope of practice would make them less likely to detect acute medical issues.

\section{Methods}

\section{Study design and data sources}

We conducted a population-based case-crossover study among adult patients receiving home care within the HamiltonNiagara-Haldimand-Brant health region in Ontario. The health region includes more than 1.3 million people, accounting for roughly $11 \%$ of the population of Ontario, and has the largest number of adults older than 65 years in the province. The region contains more than 10 municipalities with wide variations in population density, socioeconomic status and access to care from tertiary centres. Ontario provides universal access to emergency department and home care services via the publicly funded provincial health care system.

We used multiple linked population-based health administrative databases. Home care records were obtained from the Client Health and Related Information System, which is the health administrative database used by Ontario's publicly funded home care system. ${ }^{15}$ Information on emergency department visits and hospital stays were obtained from the National Ambulatory Care Reporting System and the Discharge Abstract Database, which contain standardized reporting for all emergency department visits and acute hospital admissions in Ontario, respectively. ${ }^{16,17}$ The 3 databases are regularly checked for validity and have been used extensively in research. ${ }^{16-24}$

Regional versions of the administrative databases were accessed at the Health Data Library at McMaster University. Records were linked at the individual level using encrypted, unique identifiers.

\section{Participants}

We constructed a population-based cohort of every day that each patient aged 19 years and older and receiving home care was eligible to receive service in the Ontario region between Jan. 1, 2015, and Dec. 31, 2015. Home care billing records were used to identify which home care services a patient received on each day, including nursing, personal support and therapies (physiotherapy, occupational therapy, speech and language therapy, nutritional therapy and social work). The cohort was linked to emergency department records to identify any day that a patient visited the emergency department after $5 \mathrm{pm}$ and to identify the Canadian Triage and Acuity Scale (CTAS) ${ }^{25}$ score, discharge disposition and primary diagnosis (International Statistical Classification of Diseases and Related Health Problems, 10th revision [ICD-10-CA] $)^{26}$ associated with the visit. In the rare case that a patient visited the emergency department twice after $5 \mathrm{pm}$ on the same day, only the first visit was included. Days that a patient was admitted to hospital were excluded from the cohort.

We used existing administrative service categories to stratify the cohort into "long stay," "short stay" and palliative groups (Appendix 1, available at www.cmaj.ca/lookup/suppl/doi:10. 1503/cmaj.170892/-/DC1). Patients receiving palliative care were excluded from the cohort.

\section{Statistical analysis}

The case-crossover design matches an exposure period that precedes an event of interest with 1 or more control exposure periods within the same subject. ${ }^{27}$ The design is appropriate for investigating the transient effects of an intermittent exposure on acute events. ${ }^{28}$ Through self-matching, the design eliminates confounding from any fixed patient-level factors.

Cases were defined as days that a member of our cohort of patients receiving home care visited the emergency department after $5 \mathrm{pm}$. The primary exposure measured was home care visits received on the same day as the emergency department visit. Control exposure periods were identified by selecting all days in the 7 days immediately preceding the case day that the patient did not visit the emergency department after 5 pm. Each day formed a separate matched control with exposure measured as the home care services that the patient received on that day. Matched sets of case and control days were analyzed with conditional logistic regression.

The analysis was limited to emergency department visits after $5 \mathrm{pm}$ to ensure that the emergency department visits occurred after any home care visits on that day, home care visits in the evening being uncommon. Weekends and holidays were excluded from the selection of both cases and controls owing to varying exposure patterns and availability of other health care services on those days. Cases and control periods were selected separately for each type of home care service (nursing, therapies and personal support) with a requirement that the patient be actively authorized to receive the service. Patients could be authorized for all or none of the services on any day. Personal support was not studied in short-stay patients because they do not typically receive the service. Analyses were stratified by patient group and performed separately for each service type. In addition to the primary case definition of any emergency department visit after $5 \mathrm{pm}$, we also examined emergency department cases defined by discharge disposition (hospital admission v. non-hospital admission) and higher or lower acuity (CTAS score 1-3 v. 4-5). We examined effect modification by sex and self-reported health using the interaction term approach. 
Some patients visited the emergency department after $5 \mathrm{pm}$ on more than 1 day during the study period, creating dependencies between cases. To avoid violating independence assumptions, we adopted a within-cluster resampling analytic approach. ${ }^{29}$ One case and 1 matched control day were randomly selected per patient, creating a set of independent matched pairs that was analyzed with conditional logistic regression. This process was repeated 10000 times, resampling cases and control days with replacement. The ensemble of individual model results was combined according to the method of Riegar and Weinberg ${ }^{29}$ to produce overall estimates of the model parameters and associated variances. All statistical tests were 2 -tailed, and $p<0.05$ was set as the significance level.

\section{Sensitivity analysis}

We performed a sensitivity analysis to examine the robustness of the results to changes in elements of the study design. We conducted the analysis using $4 \mathrm{pm}$ and $6 \mathrm{pm}$ rather than $5 \mathrm{pm}$ as the threshold for capturing emergency department visits. We also explored the effects of selecting control periods from the 5 days, 3 days or 1 day immediately preceding the case day rather than the 7 days used in the primary analysis.

\section{Ethics approval}

We received ethics approval from the Hamilton Integrated Research Ethics Board, which is affiliated with McMaster University, St. Joseph's Healthcare Hamilton and Hamilton Health Sciences.

\section{Results}

The cohort contained 30253 long-stay and 35097 short-stay patients receiving home care. A total of 4429 unique long-stay patients contributed 5893 emergency department visits to the case-crossover analysis, and 2836 unique short-stay patients contributed 3476 visits. The characteristics of patients contributing cases to the analysis can be found in Table 1. Long-stay patients were largely frail older adults with multiple chronic conditions, functional impairments and ongoing home support needs. Short-stay patients tended to be younger, post-acute care patients with short-term care needs, such as wound care, intravenous medication administration or rehabilitation. Clinical assessment data were available for only 3958 (89.4\%) long-stay patients and 2676 (94.4\%) short-stay patients because some patients were discharged before a clinical assessment was completed (e.g., death or hospital admission). Long-stay patients had a median age of 81 years, and $61.6 \%$ were female. Short-stay patients were younger, with a median age of 66 , and had a slight preponderance of women (51.6\%).

The number of cases available for analysis varied by the home care service examined, because patients had to be actively authorized to receive the service for a day to be included as a case. A matrix of the total cases and controls and exposed cases and controls by emergency department visit by outcome and type of home care service can be found in Table 2 .

Home care nursing visits were significantly associated with a greater likelihood of same-day emergency department visits after $5 \mathrm{pm}$ in both long-stay (odds ratio [OR] 1.32, 95\% confidence interval $[\mathrm{Cl}] 1.17-1.48$ ) and short-stay patients (OR 1.22, 95\% Cl 1.07-1.39) (Figure 1). In both patient groups, the effect was stronger in visits to the emergency department that did not

Table 1: Characteristics of patients receiving home care who visited the emergency department

\begin{tabular}{|c|c|c|}
\hline \multirow[b]{2}{*}{ Characteristic } & \multicolumn{2}{|c|}{ No. $(\%)$ of patients* } \\
\hline & $\begin{array}{l}\text { Long stay } \\
n=3958 \dagger\end{array}$ & $\begin{array}{l}\text { Short stay } \\
n=2676 \neq\end{array}$ \\
\hline \multicolumn{3}{|l|}{ Demographic } \\
\hline Age, median (IQR), yr & $81(19)$ & $66(26)$ \\
\hline Sex, female & $2438(61.6)$ & $1381(51.6)$ \\
\hline Lives alone & $1305(33.0)$ & $612(22.9)$ \\
\hline \multicolumn{3}{|l|}{ Health } \\
\hline $\begin{array}{l}\text { Impairment in activities of daily } \\
\text { living§ }\end{array}$ & $3536(89.3)$ & $967(36.1)$ \\
\hline Cognitive impairment $₫$ & $2374(60.0)$ & $300(11.2)$ \\
\hline Dyspnea & $1377(34.8)$ & $736(27.5)$ \\
\hline Poor self-reported health & $1056(26.7)$ & $575(21.5)$ \\
\hline Fall in last $90 \mathrm{~d}$ & $1890(47.8)$ & - \\
\hline Mood symptoms ${ }^{\star *}$ & $1799(45.5)$ & - \\
\hline Wandering & $121(3.1)$ & - \\
\hline Aggressive behaviourt† & $427(10.8)$ & - \\
\hline Weight loss $\ddagger$ & $379(9.6)$ & - \\
\hline No. of medications, mean \pm SD & $7.39 \pm 2.09$ & - \\
\hline
\end{tabular}

\section{Informal caregiver status}

Caregiver distress§§

895 (22.6)

Informal care per day, mean \pm SD, $\mathrm{h}$

$2.65 \pm 2.92$

\section{Diagnosis}

Cardiovascular

2311 (58.4)

Dementia

$869(22.0)$

Neurologic

$438(11.1)$

Musculoskeletal

$2680(67.7)$

Psychiatric

$1055(26.7)$

Cancer

$588(14.9)$

Diabetes

$1271(32.1)$

COPD

$982(24.8)$

Note: $\mathrm{COPD}=$ chronic obstructive pulmonary disease, $\mathrm{IQR}$ = interquartile range,

$\mathrm{SD}=$ standard deviation.

*Unless stated otherwise.

†Data available for 3958 of 4429 patients.

$\ddagger$ Data available for 2676 of 2836 patients.

§upervision or any assistance in bathing, dressing lower body, personal hygiene or locomotion.

IModified independence or impairment in cognitive skills for daily decision-making.

**Depression Rating Scale score $>0$.

††Verbal abuse, physical abuse, socially inappropriate behaviour or resistance to care in last 3 days.

$\ddagger$ Unintended weight loss of $\geq 5 \%$ in the last 30 days or $\geq 10 \%$ in the last 180 days. $\S \S$ Caregiver expresses feelings of distress, anger or depression. 
Table 2: Number of cases and controls and exposed cases and controls by outcome, patient group and service type

No. of patients (exposed patients)

\begin{tabular}{|c|c|c|c|c|c|}
\hline \multirow[b]{2}{*}{ Outcome } & \multicolumn{3}{|c|}{ Long stay } & \multicolumn{2}{|c|}{ Short stay } \\
\hline & Nursing & Therapy* & Personal support & Nursing & Therapy* \\
\hline \multicolumn{6}{|l|}{ Cases } \\
\hline ED visit & $2610(1014)$ & $2309(262)$ & $3737(2453)$ & $2430(971)$ & $1128(156)$ \\
\hline ED visit, admission & $1029(408)$ & 1025 (129) & $1552(1,032)$ & $614(235)$ & $454(64)$ \\
\hline ED visit, no admission & $1581(606)$ & $1284(133)$ & $2185(1421)$ & $1816(736)$ & $674(92)$ \\
\hline $\begin{array}{l}\text { ED visit, CTAS score } \\
1-3\end{array}$ & $2243(855)$ & $2063(234)$ & $3280(2157)$ & $1843(676)$ & 956 (129) \\
\hline $\begin{array}{l}\text { ED visit, CTAS score } \\
4-5\end{array}$ & 367 (159) & $246(28)$ & 457 (296) & $587(295)$ & $172(27)$ \\
\hline \multicolumn{6}{|l|}{ Controls } \\
\hline ED visit & 10784 (3638) & $9520(1092)$ & $16524(11011)$ & $8212(2880)$ & $4333(491)$ \\
\hline ED visit, admission & $4382(1619)$ & $4201(542)$ & 6895 (4696) & 2377 (852) & $1844(227)$ \\
\hline ED visit, no admission & $6475(2051)$ & $5361(553)$ & $9701(6358)$ & $5870(2042)$ & $2504(266)$ \\
\hline $\begin{array}{l}\text { ED visit, CTAS score } \\
1-3\end{array}$ & 9356 (3139) & 8550 (985) & $14588(9740)$ & $6629(2175)$ & $3732(415)$ \\
\hline $\begin{array}{l}\text { ED visit, CTAS score } \\
4-5\end{array}$ & $1493(515)$ & $1011(111)$ & $1989(1298)$ & $1651(738)$ & 624 (79) \\
\hline
\end{tabular}

result in a hospital admission (long stay: OR $1.50,95 \% \mathrm{Cl} 1.29-$ 1.76; short stay: OR $1.30,95 \% \mathrm{Cl} 1.11-1.52)$. The effect was also stronger in emergency department visits with a CTAS score of 4 or 5 in the long-stay patient group (OR 1.63, 95\% Cl 1.20-2.21).

The association between home care nursing visits and emergency department visits was not significant when emergency department visits were restricted to those that resulted in a hospital admission. There were also no significant associations between any type of emergency department visit and home care therapies or personal support visits.

Primary diagnoses for emergency department visits that occurred on the same day as home care nursing visits were broad, with the top 10 diagnoses accounting for only $31.37 \%$ of all diagnoses among long-stay patients and $37.78 \%$ among short-stay patients (Appendix 2, available at www.cmaj.ca/lookup/suppl/ doi:10.1503/cmaj.170892/-/DC1). There was no consistent, appreciable effect modification by sex or self-reported health (Appendices 3 and 4, available at www.cmaj.ca/lookup/suppl/doi:10.1503/ cmaj.170892/-/DC1).

\section{Sensitivity analysis}

Using a threshold of $4 \mathrm{pm}$ or $6 \mathrm{pm}$ rather than $5 \mathrm{pm}$ for emergency department visits did not have a meaningful effect on the results (Appendix 5, available at www.cmaj.ca/lookup/suppl/ doi:10.1503/cmaj.170892/-/DC1). The odds ratios between nursing visits and emergency department visits produced using the
$6 \mathrm{pm}$ threshold tended to be slightly smaller than those from the $5 \mathrm{pm}$ threshold, which is in line with expectations that a transient association would attenuate over time. Selecting control exposures from the 5 days, 3 days or 1 day immediately preceding the case day yielded similar results to using 7 days (Appendix 6, available at www.cmaj.ca/lookup/suppl/doi:10.1503/cmaj. 170892/-/DC1).

\section{Interpretation}

Receiving home care nursing visits during the day was associated with an increased likelihood of visiting the emergency department between $5 \mathrm{pm}$ and midnight of the same day. Stronger associations were observed for emergency department visits that did not result in a hospital admission and for visits with a CTAS score of 4 or 5 among long-stay patients.

This study examined the transient effect of home care visits on emergency department use, considering only emergency department visits that occurred on the same day as a home care visit. Accordingly, our results cannot be compared with studies that looked at emergency department use over periods of weeks and months. The results of the study supported our hypothesis that home care nursing would be associated with a higher likelihood of same-day emergency department use. An emergency department visit is not necessarily a negative outcome, but may be if patients could more appropriately receive treatment in the 


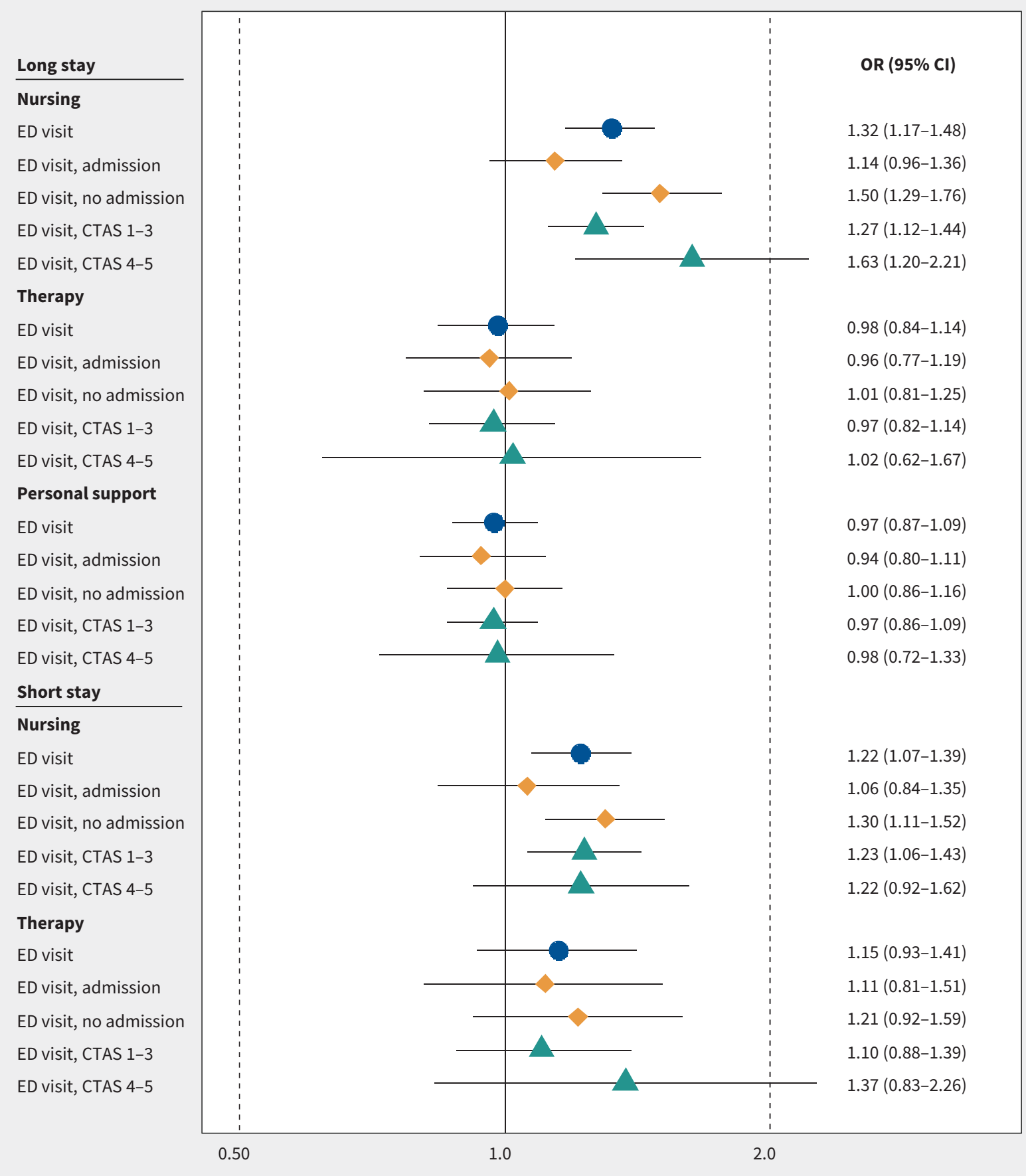

Figure 1: Emergency department (ED) visits after $5 \mathrm{pm}$ by outcome, patient group and service type. $\mathrm{Cl}=$ confidence interval, $\mathrm{CTAS}=\mathrm{Canadian}$ Triage Acuity Scale, OR = odds ratio.

community setting by their usual providers. Although it is difficult to determine the appropriateness of an emergency department visit from administrative data, the stronger associations noted for non-hospital admission and less acute emergency department visits suggests that some patients likely could have received treatment in less acute settings.
Our findings correspond with previous reports on the challenges of nursing care in the community, such as limited time and the lack of direct management of clinical problems. ${ }^{30}$ Currently, care and monitoring outside of the home care visits is predominantly assumed by the patient and family, who would require self-care knowledge and skills to prevent unplanned 
hospital admissions. ${ }^{21}$ The involvement of more nurse practitioners in home care or on-call primary care could address some of the acute needs that would otherwise result in an emergency department visit. Additionally, the current model of care for patients not receiving palliative care (nearly all) does not operate with full integration of primary care. Home care staff and patients may have no viable option other than to proceed to the emergency department, because there are limited mechanisms in place for timely access to diagnostics and physician support to address or consult on emergent problems. Better integration with primary care may also support greater continuity of care, which has been associated with lower emergency department use. ${ }^{31,32}$

Our findings support the need for further investigation into the reason or reasons that home care nursing visits are associated with a higher likelihood of same-day emergency department visits and into the appropriateness of these visits. Experimental studies are needed to test the cost-effectiveness of home and primary care models that support safe and timely access to community-based care when nonurgent clinical issues arise.

\section{Limitations}

This study has several limitations. First, given that the casecrossover design examines only cases, only patients who visited the emergency department after 5 pm contributed to the analysis. Also, the data sources used in this study contained the billing records for all publicly funded home care in the region, but no information on privately funded home care that a patient may have been receiving at the same time. Finally, the use of regional data prevents the capture of emergency department visits by patients who resided in the region but went to the emergency department in another region. However, our analyses suggest that potential confounding was rare and would only serve to make our results more conservative.

\section{Conclusion}

We found that patients receiving home care were more likely to visit the emergency department during the evening on days that they received a home care nursing visit. The association trended stronger for emergency department visits that did not result in a hospital admission and for lower-acuity visits among patients with ongoing care needs. Future work should continue to explore the mechanisms by which home care nursing visits are associated with emergency department use and other outcomes, incorporating additional effect modifiers, such as primary care access.

\section{References}

1. Gruneir A, Silver MJ, Rochon PA. Emergency department use by older adults: a literature review on trends, appropriateness, and consequences of unmet health care needs. Med Care Res Rev 2011;68:131-55.

2. Latham LP, Ackroyd-Stolarz S. Emergency department utilization by older adults: a descriptive study. Can Geriatr J 2014;17:118-25.

3. Moons $\mathrm{P}$, Arnauts $\mathrm{H}$, Delooz $\mathrm{HH}$. Nursing issues in care for the elderly in the emergency department: an overview of the literature. Accid Emerg Nurs 2003;11:112-20.

4. Aminzadeh F, Dalziel WB. Older adults in the emergency department: a systematic review of patterns of use, adverse outcomes, and effectiveness of interventions. Ann Emerg Med 2002;39:238-47.
5. Samaras N, Chevalley T, Samaras D, et al. Older patients in the emergency department: a review. Ann Emerg Med 2010;56:261-9.

6. Hwang U, Shah MN, Han JH, et al. Transforming emergency care for older adults. Health Aff (Millwood) 2013;32:2116-21.

7. Wilson D, Truman C. Comparing the health services utilization of long-termcare residents, home-care recipients, and the well elderly. Can J Nurs Res 2005;37:138-54.

8. Improving access to emergency care: addressing system issues. Toronto: Physician Hospital Care Committee; 2006. Available: www.health.gov.on.ca/en/ common/ministry/publications/reports/improving_access/improving_access. pdf (accessed 2016 Nov. 30).

9. Under pressure: emergency department performance in Ontario. Toronto: Health Quality Ontario; 2016. Available: http://underpressure.hqontario.ca (accessed 2016 Nov. 30).

10. Godwin M, Gadag V, Pike A, et al. A randomized controlled trial of the effect of an intensive 1-year care management program on measures of health status in independent, community-living old elderly: the Eldercare project. Fam Pract 2016;33:37-41.

11. Béland $\mathrm{F}$, Bergman $\mathrm{H}$, Lebel $\mathrm{P}$, et al. Integrated services for frail elders (SIPA): a trial of a model for Canada. Can J Aging 2006;25:5-42.

12. Seow $H$, Barbera L, Pataky R, et al. Does increasing home care nursing reduce emergency department visits at the end of life? A population-based cohort study of cancer decedents. J Pain Symptom Manage 2016;51:204-12.

13. Optimizing the role of nursing in home health. Ottawa: Canadian Nursing Association; 2013. Available: https://cna-aiic.ca/ /media/cna/page-content/pdf-en/ optimizing_the_role_of_nursing_in_home_health_e.pdf?la=en (accessed 2017 July 20).

14. CMA pushes home care fund. Ottawa: Canadian Medical Association; 2016 Available: www.demandaplan.ca/cma_pushes_home_care_fund (accessed 2017 July 20).

15. Zvaniga C. Chris: a community health care success story. Toronto: BPS Books; 2011.

16. Database background and general data limitations documentation - National Ambulatory Care Reporting System (NACRS) 2007-2008: executive summary. Ottawa: Canadian Institute for Health Information; 2007. Available: www.cihi. ca/sites/default/files/nacrs_exec_summ_2007-2008_en_0.pdf (accessed 2017 May 30).

17. Data quality documentation, discharge abstract database - multi-year information. Ottawa: Canadian Institute for Health Information; 2012. Available: www.cihi.ca/en/dad_multi-year_en.pdf (accessed 2017 May 30).

18. Seow H, Brazil K, Sussman J, et al. Impact of community based, specialist palliative care teams on hospitalisations and emergency department visits late in life and hospital deaths: a pooled analysis. BMJ 2014;348:g3496.

19. Guttmann A, Schull MJ, Vermeulen MJ, et al. Association between waiting times and short term mortality and hospital admission after departure from emergency department: population based cohort study from Ontario, Canada. BMJ 2011;342:d2983.

20. Gibson D, Richards H, Chapman A. The National Ambulatory Care Reporting System: factors that affect the quality of its emergency data. Int J Inf Qual 2008; 2:97-114.

21. Doran DM, Hirdes JP, Blais R, et al. Adverse events among Ontario home care clients associated with emergency room visit or hospitalization: a retrospective cohort study. BMC Health Serv Res 2013;13:227.

22. Seow H, Barbera L, Howell D, et al. Using more end-of-life homecare services is associated with using fewer acute care services: a population-based cohort study. Med Care 2010;48:118-24.

23. de Oliveira C, Bremner KE, Pataky R, et al. Understanding the costs of cancer care before and after diagnosis for the 21 most common cancers in Ontario: a population-based descriptive study. CMAJ Open 2013;1:E1-8.

24. Cohen E, Berry JG, Camacho X, et al. Patterns and costs of health care use of children with medical complexity. Pediatrics 2012;130:e1463-70.

25. Bullard MJ, Chan T, Brayman C, et al.; Members of the CTAS National Working Group. Revisions to the Canadian emergency department triage and acuity scale (CTAS) guidelines. CJEM 2014;16:485-9. 
26. Volume 1 - International Statistical Classification of Diseases and Related Health Problems, tenth revision, Canada (ICD-10-CA) - tabular list. Ottawa: Canadian Institute for Health Information; 2009. Available: www.cihi.ca/en/ icd_10_ca_vol1_2009_en.pdf (accessed 2017 June 4).

27. Maclure M. The case-crossover design: a method for studying transient effects on the risk of acute events. Am J Epidemiol 1991;133:144-53.

28. Lombardi DA. The case-crossover study: a novel design in evaluating transient fatigue as a risk factor for road traffic accidents. Sleep 2010;33:283-4.

29. Rieger RH, Weinberg CR. Analysis of clustered binary outcomes using withincluster paired resampling. Biometrics 2002;58:332-41.
30. Sun W, Doran DM, Wodchis WP, et al. Examining the relationship between therapeutic self-care and adverse events for home care clients in Ontario, Canada: a retrospective cohort study. BMC Health Serv Res 2017;17:206.

31. Ionescu-Ittu R, McCusker J, Ciampi A, et al. Continuity of primary care and emergency department utilization among elderly people. CMAJ 2007;177: 1362-8.

32. McCusker J, Roberge D, Lévesque J-F, et al. Emergency department visits and primary care among adults with chronic conditions. Med Care 2010;48: 972-80.

\section{Competing interests: None declared.}

This article has been peer reviewed.

Affiliations: Department of Health Research Methods, Evidence, and Impact (Jones, Schumacher, Seow, Costa), McMaster University, Hamilton, Ont.; Institute for Clinical Evaluative Sciences (Bronskill, Campitelli); Institute of Health Policy, Management \& Evaluation (Bronskill), Dalla Lana School of Public Health, University of Toronto, Toronto, Ont.; School of Public Health and Health Systems (Poss), University of Waterloo, Waterloo, Ont.; Departments of Oncology (Seow) and Medicine (Costa), McMaster University, Hamilton, Ont.
Contributors: Andrew Costa and Aaron Jones conceived the study and developed the design in consultation with the other authors. Aaron Jones completed the analysis. All of the authors contributed to the interpretation of data. Aaron Jones drafted the manuscript, which all of the authors revised. All of the authors approved the final version to be published and agreed to be accountable for all aspects of the work.

Funding: Andrew Costa is supported by the Schlegel Chair in Clinical Epidemiology and Aging, McMaster University. This study was funded by a grant from the Canadian Frailty Network (TG2015-15P) and the Canadian Institutes for Health Research (148933). The opinions and conclusions expressed in this article are those of the authors and do not necessarily reflect the views of the contributing centres or funders.

Preliminary findings from this study were presented at the Canadian Association for Health Services and Policy Research Annual Conference, Toronto, Ont., May 24, 2017, and the Achieving Excellence Together Conference, Toronto, Ont., June 15, 2017.

Accepted: Nov. 28, 2017

Correspondence to: Andrew Costa, acosta@ mcmaster.ca 